\title{
Effectiveness of Online Learning of Construction Equipment Courses During the COVID-19 Pandemic
}

\author{
Hasan Dani ${ }^{1,{ }^{*}}$ Puguh Novi Prasetyono ${ }^{1}$ Mas Suryanto HS ${ }^{1}$ Danayanti Azmi Dewi ${ }^{1}$ \\ Nusantara ${ }^{1}$ Amanda Ristriana Pattisinai ${ }^{1}$ Feriza Nadiar ${ }^{1}$
}

\author{
${ }^{1}$ Department of Civil Engineering, Universitas Negeri Surabaya, Surabaya, Indonesia \\ "Corresponding author. Email: hasandani@unesa.ac.id
}

\begin{abstract}
The whole society is affected by the pandemic of coronavirus or COVID-19, even in Indonesia's education sector. One of the government's policies to constrict the spread of COVID-19 is by physical distancing. The education sector's impact is which must be using an online learning platform, which is also implemented by Universitas Negeri Surabaya. Online learning tends to be sudden, so it is necessary to identify online learning's effectiveness, both about the use of media and the methods used. This study aims to analyze the effectiveness of online learning implementation in a civil engineering construction equipment course during COVID-19. This study is descriptive with a quantitative approach. The respondents of this study were students who carried out online learning of construction equipment courses. The data collection used a questionnaire and the data analysis by quantitative descriptive analysis. The results of student responses show that of the six components, there are three components to get good effectiveness criteria: Motivation, Method, and Problem of Online Learning. Furthermore, other components that get great the effectiveness criteria are the Implementation, the Suitability, and the Advantages of Online Learning. It can conclude that there are no component criteria that have excellent effectiveness.
\end{abstract}

Keywords: COVID-19, Online Learning, Social Distancing, Construction Equipment

\section{INTRODUCTION}

The coronavirus or COVID-19 has an impact on the whole community, even in Indonesia's education sector. Since Indonesian President Joko Widodo announced the first case of COVID-19 in Indonesia on March 2, 2020, Jokowi has appealed to the public to reduce activities outside the home to prevent the spread of COVID-19 in Indonesia. Indonesian people suggest doing social distancing to prevent the spread of the coronavirus. With social distancing, it positively impacts the learning process that must go online. One of those who implement online learning policies is Universitas Negeri Surabaya (UNESA).

The new era of online learning services is forming by ubiquitous learning, social networks (communities), mobile technologies, and personalized knowledge management [1]. The teaching and learning process at Universitas Negeri Surabaya carried out online using elearning, vi-learning, mailing lists, chat groups, video conferences, and others. Online learning is considered as alternative learning independently for assisting or improving the traditional classroom teaching [2]. With the application of online learning, the lecturer expected to be creative in making media, materials, and evaluation methods used so the learning process could run effectively. From the teacher's point of view, online learning requires new pedagogic skills so that learning can run effectively [3]. It makes many things that need to review to achieve more effective online learning.

However, to achieve adequate online learning certainly depends on several factors [4][5]. Research previously conducted shows that based on instruments to measure student satisfaction, factors that can influence the effective online learning process are content, learning community, learner interface, and personalization [4]. While another previous research present that the effectiveness of online learning depends on nine factors. The factors were personal characteristics and system instruction; participant 
motivation and system interaction; a range of instructional materials and accuracy; webpage design and display of instruction materials; e-learning environment; webpage connection; course quality and work influences; learning records; and instruction evaluating materials [6].

One of the courses gone online is the Construction Equipment programmed by the Civil Engineering Department at Universitas Negeri Surabaya. The implementation of online learning in the teaching and learning process is suddenly and unfamiliar for both students and lecturers. Based on the previous explanation, it is necessary to improve online learning's effectiveness, both about the media or the methods used. This study aims to analyze the effectiveness of online learning implementation in a civil engineering construction equipment course during COVID-19. Moreover, what improvement considered in the application of bold further online learning.

\section{METHOD}

This study is a descriptive method with a quantitative approach. The research data collected from an online questionnaire about the implementation satisfaction of online learning and will analyze using quantitative descriptive analysis [7]. The study carries at the Department of Civil Engineering, Faculty of Engineering, Universitas Negeri Surabaya. The respondents of this study were students who carried out online learning of Construction Equipment Courses during the COVID-19 pandemic in the second semester of 2019/2020 academic year. The number of respondents who filled the instrument satisfaction was 69 students. The questionnaires already developed by the research team and validated by the experts. The respondents' instrument satisfaction consists of six components: the motivation, the method, the problem, the implementation, the suitability, and the advantages of online learning [8].

First of all, determine the highest, the lowest, the mean, and the standard deviation of the ideal score[9]. The score is from 1 to 5 for each question, represents the category of satisfaction from respondents. The category of satisfaction divide from the lowest score means poor, fair, good, great, and excellent for the highest score [7]. Each aspect that studied will have a different number of scores depending on the sum of questions representing the aspect [10]. The sum of the questions represents that each aspect or component is shown in Table 1.

The highest of the ideal score is the multifunction product from the sum of questions and the maximum score[11]. Otherwise, the lowest of the ideal score is the multifunction product from the sum of questions and the minimum score. Equation (1) to calculate the mean of the ideal score (Mi), while Equation (2) to calculate the standard deviation of the ideal score (SDi) [12]. The score can be shown in Table 1 .

$M_{i}=\frac{1}{2}$ (the highest of the ideal score + the lowest of the ideal score)

$S D_{i}=\frac{1}{6}$ (the highest of the ideal score the lowest of the ideal score)

Table 1. Result Calculation of Ideal Score Based On The Sum Of Question

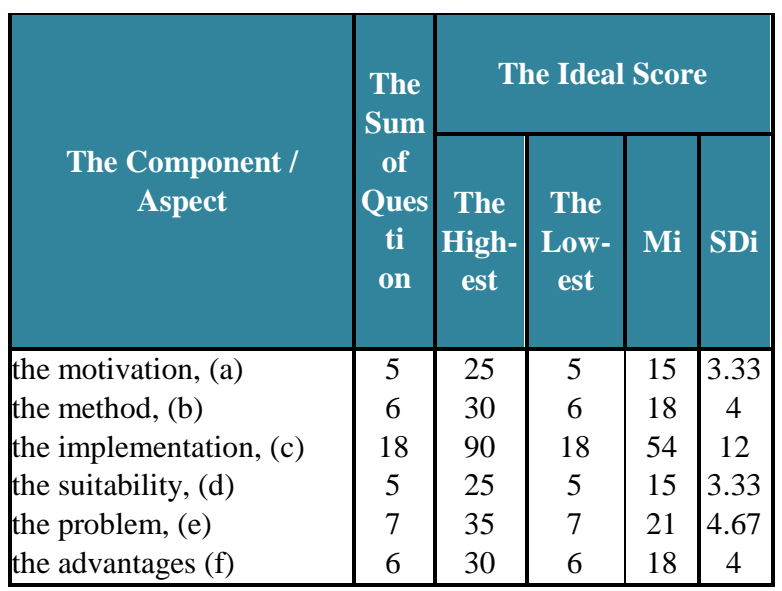

Table 2. Category the Effectiveness Of Each Component

\begin{tabular}{|c|c|c|c|c|c||}
\hline \multirow{2}{*}{ Category } & \multicolumn{5}{|c|}{ Range of Score } \\
\cline { 2 - 6 } & The Component & $(\boldsymbol{a}) ;(\boldsymbol{d})$ & $(\boldsymbol{b}) ;(\boldsymbol{f})$ & $(\boldsymbol{e})$ & $(\boldsymbol{c})$ \\
\hline Excellent & $\mathrm{X}>\mathrm{Mi}+1,5 \mathrm{SDi}$ & $\mathrm{X}>20$ & $\mathrm{X}>24$ & $\mathrm{X}>28$ & $\mathrm{X}>72$ \\
\hline \multirow{2}{*}{ Great } & $\mathrm{Mi}+0,5 \mathrm{SDi}<\mathrm{X}$ & $17<\mathrm{X}$ & $20<\mathrm{X}$ & $23,3<$ & $60<\mathrm{X}$ \\
& $<\mathrm{Mi}+1,5 \mathrm{SDi}$ & $<20$ & $<24$ & $\mathrm{X}<28$ & $<72$ \\
\hline \multirow{2}{*}{ Good } & $\mathrm{Mi}-0,5 \mathrm{SDi}<\mathrm{X}<$ & $13<\mathrm{X}<$ & $16<\mathrm{X}<$ & $18,7<\mathrm{X}$ & $48<\mathrm{X}$ \\
& $\mathrm{Mi}+0,5 \mathrm{SDi}$ & 17 & 20 & $<23,3$ & 60 \\
\hline \multirow{2}{*}{ Fair } & $\mathrm{Mi}-1,5 \mathrm{SDi}<\mathrm{X}<$ & $10<\mathrm{X}<$ & $12<\mathrm{X}<$ & $14<\mathrm{X}<$ & $36<\mathrm{X}<$ \\
& $\mathrm{Mi}-0,5 \mathrm{SDi}$ & 13,3 & 16 & 18,7 & 48 \\
\hline Poor & $\mathrm{X}<\mathrm{Mi}-1,5 \mathrm{SDi}$ & $\mathrm{X}<10$ & $\mathrm{X}<12$ & $\mathrm{X}<14$ & $\mathrm{X}<36$ \\
\hline
\end{tabular}

The following step is to make categorized the effectiveness based on the range score be demanded. The result can be shown in Table 2. After the category of satisfaction is divided based on the range of scores, the next process is to analyze the student's response in each component. The average total score in each aspect will determine the category of the effectiveness of the online learning process [13]

\section{RESULTS AND DISCUSSION}

This study aims to know the effectiveness of online learning of Construction Equipment Courses during the COVID-19 Pandemic. The result and discussion will divide into six components, which can perceive the effectiveness of online learning from analyzing the questionnaire. The questionnaire complete by a total of 
69 students of Construction Equipment Courses as respondents. Assessment performs by comparing the average scores with the assessment criteria in Table 2 in each component [14].

\subsection{The Motivation of Online Learning}

There are five questions in the questionnaire to get information about the motivation of online learning. The motivation describes the enthusiasm and interest of students to attend the classes online. Student responses to the components of motivation get a total score of 1153, with an average number of 16.71 . The result shows in Table 3. Based on Table 2, if the average score is 16.71 , it categorized to good.

Table 3. Description of Online Learning

\begin{tabular}{|l|l|l|}
\hline Number of question & Sum of score & \multicolumn{1}{|c|}{$\begin{array}{c}\text { Average of } \\
\text { score }\end{array}$} \\
\hline 1 & 260 & 3.77 \\
\hline 2 & 214 & 3.10 \\
\hline 3 & 183 & 2.65 \\
\hline 4 & 274 & 3.97 \\
\hline 5 & 222 & 3.22 \\
\hline Total & 1153 & 16.71 \\
\hline
\end{tabular}

\subsection{The Method of Online Learning}

There are six methods of online learning using in this study. Each type of method that used in this course gets the effectiveness score from the students. The six methods are:

1. independent learning (lecturer share the study materials, student do self-learning)

2. learning by assignment (lecturer share the study materials and the assignment, student do the assignment)

3. discussion by chat group (lecturer share the study materials, open a discussion session with chat group platform)

4. discussion by video conference (lecturer share the study materials, open a discussion session with the video conference platform)

5. guided with a chat group (lecturer teaching the study materials with chat group platform)

6. guided with video conference (lecturer teaching the study materials with the video conference platform) The method describes students' interest in each type of online learning platform used by the lecturer of the course.

Student responses to the components of method get a total score of 1224 , with an average number of 17.74 .
The result shows in Table 4. Based on Table 2, if the average score is 17.74 , it categorized to good.

Table 4. Description Data of Method Components In Learning Student Respond

\begin{tabular}{|c|c|c|}
\hline $\begin{array}{c}\text { Number of } \\
\text { question }\end{array}$ & Sum of score & $\begin{array}{c}\text { Average of } \\
\text { score }\end{array}$ \\
\hline 1 & 145 & 2.10 \\
\hline 2 & 157 & 2.28 \\
\hline 3 & 202 & 2.93 \\
\hline 4 & 247 & 3.58 \\
\hline 5 & 184 & 2.67 \\
\hline 6 & 289 & 4.19 \\
\hline Total & 1224 & $\mathbf{1 7 . 7 4}$ \\
\hline
\end{tabular}

\subsection{The Implementation of Online Learning}

There are eighteen questions in the questionnaire to get information about the implementation of online learning. The implementation describes the easiness and understanding of the study materials through the implementation of the classes online, which are as follows:

1. easiness in access to the study materials and doing the independent learning

2. understanding of some study materials which are learning outcomes, calculation and recitation materials, and other information

3. understanding the media learning platform used although PowerPoint or video

4. ease in understanding the content of materials in tables, charts, and practice questions,

5. classroom management interrelationships in understanding the study materials, concentrations while learning, the assessment, freedom to asking and getting feedback from the lecturer.

Student responses to the components of implementation get a total score of 4425 , with an average number of 64.13. The result shows in Table 5 . Based on Table 2, if the average score is 64.13 , it categorized to great.

Table 5. Description Data of Implementation Components in Online Learning Student Respond

\begin{tabular}{|c|c|c|}
\hline $\begin{array}{c}\text { Number } \\
\text { of } \\
\text { question }\end{array}$ & $\begin{array}{c}\text { Sum of } \\
\text { score }\end{array}$ & $\begin{array}{c}\text { Average of } \\
\text { score }\end{array}$ \\
\hline 1 & 259 & 3.75 \\
\hline 2 & 261 & 3.78 \\
\hline 3 & 226 & 3.28 \\
\hline 4 & 209 & 3.03 \\
\hline 5 & 233 & 3.38 \\
\hline 6 & 234 & 3.39 \\
\hline 7 & 241 & 3.49 \\
\hline 8 & 279 & 4.04 \\
\hline 9 & 288 & 4.17 \\
\hline 10 & 252 & 3.65 \\
\hline 11 & 235 & 3.41 \\
\hline & & \\
\end{tabular}




\begin{tabular}{|c|c|c|}
\hline $\begin{array}{c}\text { Number } \\
\text { of } \\
\text { question }\end{array}$ & $\begin{array}{c}\text { Sum of } \\
\text { score }\end{array}$ & $\begin{array}{c}\text { Average of } \\
\text { score }\end{array}$ \\
\hline 12 & 238 & 3.45 \\
\hline 13 & 253 & 3.67 \\
\hline 14 & 284 & 4.12 \\
\hline 15 & 223 & 3.23 \\
\hline 16 & 223 & 3.23 \\
\hline 17 & 226 & 3.28 \\
\hline 18 & 261 & 3.78 \\
\hline Total & 4425 & $\mathbf{6 4 . 1 3}$ \\
\hline \multicolumn{2}{|r}{} \\
\hline
\end{tabular}

\subsection{The Suitability of Online Learning}

There are five questions with likert scale and seven questions in the questionnaire to get information about the suitable media used in online learning. The suitable media consist of some of the online platform used by the students to attend the classes online. The student responds toward the best media suitable for each objective, delivering the lecture's information, sharing the study material, conducting the lectures, doing the assignments, doing the discussion, implementing lectures with video conferences, and managing the classes. Student responses to the components of suitability get a total score of 1303 , with an average number of 18.88. The result shows in Table 6. Based on Table 2, if the average score is 18.88 , it categorized to great.

Table 6. Description Suitability Components in Online Learning Student Respond

\begin{tabular}{|l|l|l|}
\hline Number of question & Sum of score & A verage of score \\
\hline 1 & 239 & 3.46 \\
\hline 2 & 218 & 3.16 \\
\hline 3 & 298 & 4.32 \\
\hline 4 & 261 & 3.78 \\
\hline 5 & 287 & 4.16 \\
\hline Total & 1303 & $\mathbf{1 8 . 8 8}$ \\
\hline
\end{tabular}

As for the result of the best media suitable used in online learning of Construction Equipment Courses can be seen in Fig 1 to 7 bellow.

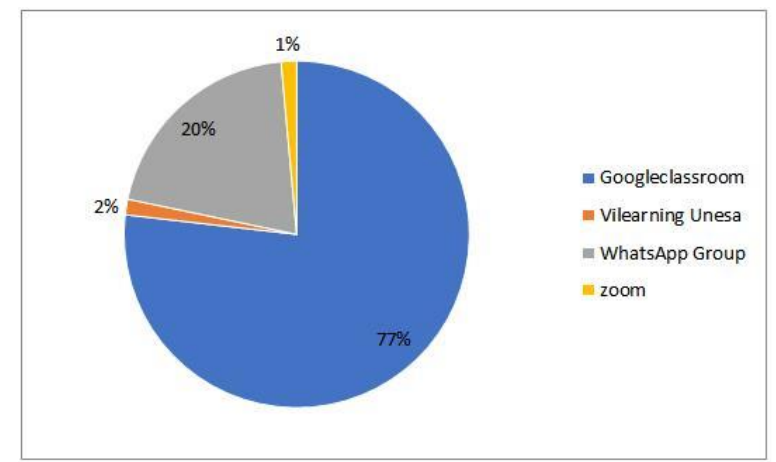

Figure 1 The student respond for the media suitable for delivering the lecture's information

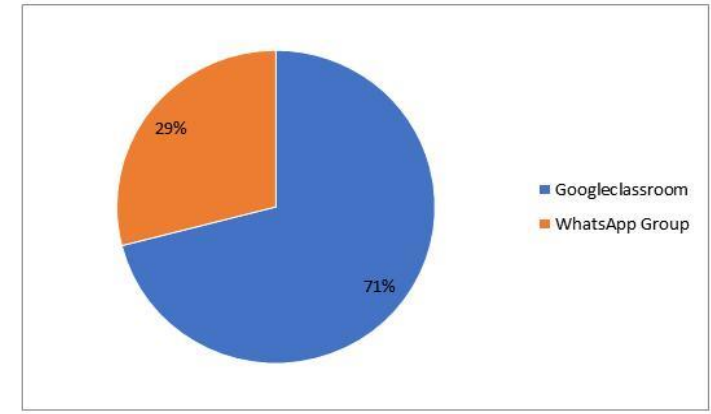

Figure 2 The student respond for the media suitable for sharing the study material

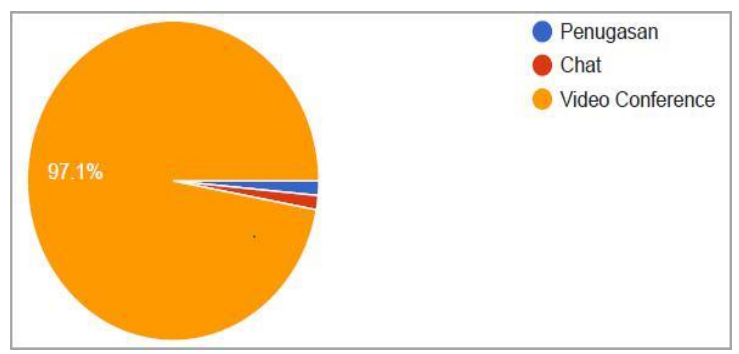

Figure 3 The student respond for the media suitable for conducting the lectures

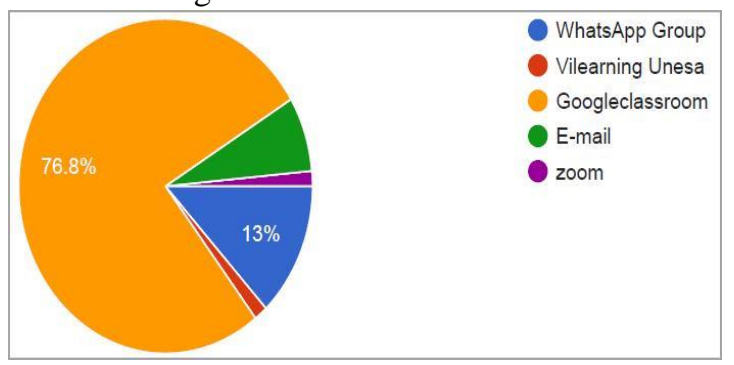

Figure 4 The student respond for the media suitable doing the assignments

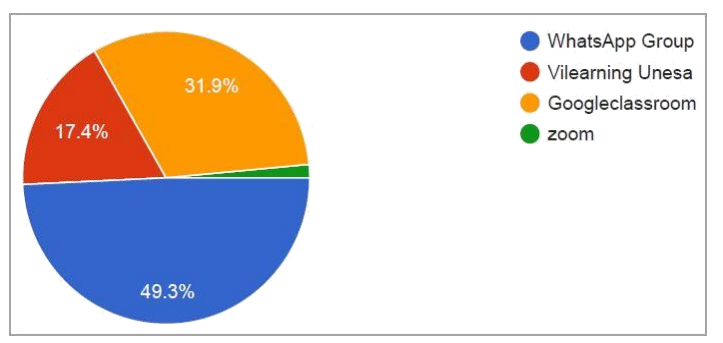

Figure 5 The student respond for the media suitable for doing the discussion

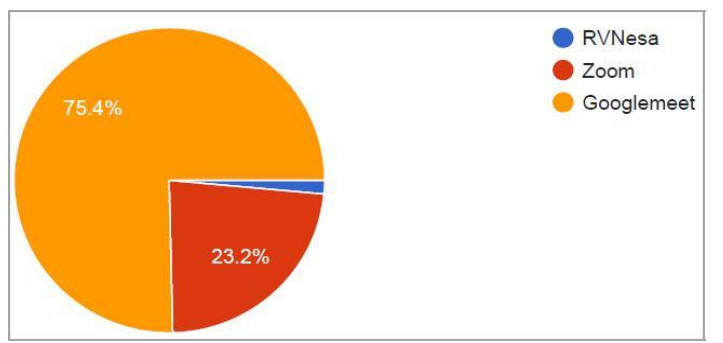

Figure 6 The student respond for the media suitable for implementing lectures with video conferences 


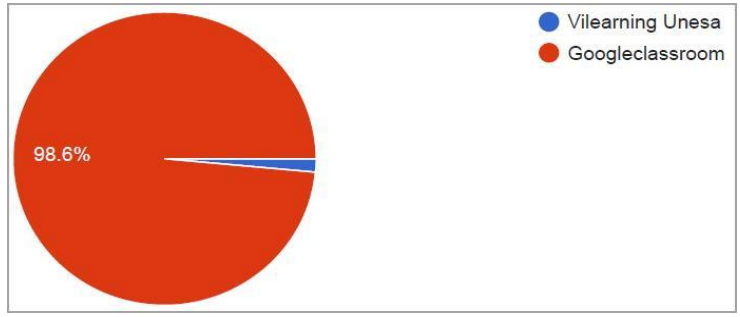

Figure 7 The student respond for the media suitable for managing the classes

\subsection{The Problem of Online Learning}

Seven items are questioned with Likert scale answers to get information about problems that occurs during online learning. Some of the problems are the internet signal and connection, the access difficulties, the more costs, the device difficulties, the boredom, and feelings of loneliness. The problems describe the obstacle that experienced by students when attending the classes online. Student responses to the components of problem get a total score of 1485 , with an average number of 21.52. The result shows in Table 7. Based on Table 2, if the average score is 21.52 , it categorized to good

Table 7. Description Data of Problem Components in Online Learning Student Respond

\begin{tabular}{|l|l|l|}
\hline Number of question & Sum of score & Average of score \\
\hline 1 & 197 & 2.86 \\
\hline 2 & 216 & 3.13 \\
\hline 3 & 174 & 2.52 \\
\hline 4 & 199 & 2.88 \\
\hline 5 & 251 & 3.64 \\
\hline 6 & 228 & 3.30 \\
\hline 7 & 220 & 3.19 \\
\hline Total & 1485 & $\mathbf{2 1 . 5 2}$ \\
\hline
\end{tabular}

\subsection{The Advantage of Online Learning}

Six items are questioned with Likert scale answers to get information about the advantages of online learning. Some advantages are:

1. ease to know the technology,

2. experienced the use of technology,

3. good understanding of study material,

4. getting the calmness feel (no other students are rowdy while attending lectures),

5. the flexibility of schedules (there are no time and space restrictions)

6. more profitable in terms of cost (though having to buy an internet data plan but cut costs to go to campus)

Student responses to the components of advantage get a total score of 1598 , with an average number of 23.16. The result shows in Table 8. Based on Table 2, if the average score is 23.16 , it categorized to great.
Table 8. Description Data of Advantage Components in Online Learning Student Respond

\begin{tabular}{|c|c|c|}
\hline Number of question & Sum of score & A verage of score \\
\hline 1 & 274 & 3.97 \\
\hline 2 & 278 & 4.03 \\
\hline 3 & 273 & 3.96 \\
\hline 4 & 268 & 3.88 \\
\hline 5 & 286 & 4.14 \\
\hline 6 & 219 & 3.17 \\
\hline Total & 1598 & $\mathbf{2 3 . 1 6}$ \\
\hline
\end{tabular}

\section{CONCLUSION}

The results of student responses show that of the six components, there are three components to get good effectiveness criteria: Motivation, Method, and Problem of Online Learning. Moreover, three other components that get great the effectiveness criteria are the Implementation of Online Learning, the Suitability of Online Learning, and the Advantages of Online Learning. From the discussion, we can conclude that there are no component criteria that have excellent effectiveness. So, we can consider improving online learning quality until getting a full effectiveness score in each component.

\section{ACKNOWLEDGMENT}

This work conduct with research funding scheme support by the Faculty of Engineering, Universitas Negeri Surabaya.

\section{REFERENCES}

[1] A. Lau and E. Tsui, "Knowledge management perspective on e-learning effectiveness,"Knowledge-BasedSyst.vol.22,no. 4, pp. 324-325, 2009.

[2] R. J. Chao and Y. H. Chen, "Evaluation of the criteria and effectiveness of distance e-learning with consistent fuzzy preference relations,"ExpertSyst.Appl., vol. 36, no. 7, pp. 10657-10662, 2009.

[3] [3] H. EL-Deghaidy and A. Nouby, "Effectiveness of a blended e-learning cooperative approach in an Egyptian teacher education Computprogramme,".Educ.vol.51,no. 3, pp. 988-1006, 2008.

[4] Y. S. Wang, H. Y. Wang,- and D. Y. Shee, "Measuring e learning systems success in an organizational context: Scale development andComputvalidation,".HumanBehav.vol.23, no. 4, pp. 1792-1808, 2007.

[5] T. Govindasamy, "Successful- implementation of e Learning PedagogicalInternetHighconsiderations,".Educ.v ol.4, no. 3-4, pp. 287-299, 2001. 
[6] G. H. Tzeng, C. H. Chiang, and C. W. Li, "Evaluating intertwined effects in e-learning programs: A novel hybrid MCDM model based on factorExpertanalysisSyst.Appl., and DEMATEL," vol. 32, no. 4, pp. 1028-1044, 2007.

[7] C. L. Ho and R. J. Dzeng, "Construction safety trainin via e-Learning: Learning effectiveness and user satisfaction," Comput. Educ., vol. 55, no. 2, pp. 858-867, 2010.

[8] M. Wrzesien and M. Alcañiz Raya, "Learning in serious virtual worlds: Evaluation of learning effectiveness and appeal to students in the EJunior Computproject,".Educ.vol.55, no. 1, pp. 178-187, 2010.

[9] J. @ E. Luaran, N. N. Samsuri, F. A. Nadzri, and K. B. M. Rom, "A Study on the Student's Perspective on the Effectiveness of Using e-learning,"Procedia-Soc. Behav. Sci., vol. 123, pp. 139-144, 2014.

[10] S. S. Liaw, "Investigating students' perceived satisfaction, behavioral intention, and effectiveness of e-learning: A case study of the BlackboardComput.Educsystem,".vol.51,no.2,pp . 864-873, 2008.

[11] A. Matei and C. Vrabie, -learning"E Platforms Supporting nthe Educational Effectiveness of Distance Learningn Programmes: A Comparative Study in ProcediaAdministrative-Soc. Sciences,"mBehav. Sci., vol. 93, pp. 526-530, 2013.

[12] Y. Ren, Z. xia Dai, X. huan Zhao, M. ming Fei, and W. tian Gan, "Exploringlinecourseapplicabilityanassessmenton to assist learners in course selection and learning effectiveness improving in elearning,"Learn.Individ. Differ., vol. 60, no. March, pp. 56-62, 2017.

[13] T. H. Wang, n"Developingassessment-centered- a Learning system for improving stu Comput. Educ., vol. 73, pp. 189-203, 2014.

[14] V. Sahasrabudhe and S. Kanung choice for elearning effectiveness: Role of learning domain and learning style,"Comput.Educ.vol. 76, pp. 237-249,2014 